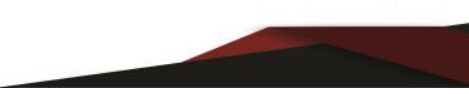

Comment

\title{
Um Estudo sobre a Pedagogia Jesuítica: o Ratio Studiorum e um breve Comparativo ao Projeto Político Pedagógico
}

Leilson Barros Oliveira ${ }^{1}$; Osvaldo Bezerra Lima Neto ${ }^{2}$; Sebastiana Micaela Amorim Lemos ${ }^{3}$

Resumo: Esse texto busca refletir em uma abordagem histórica sobre o Ratio Atque Institutio Studiorum Societatis Iesu que data de 1599, com validade para todas as escolas da Companhia de Jesus. O Ratio Studiorum significava "Regra de Estudos"; "Ordem de Estudos"; "Plano de Estudos da Companhia de Jesus", um comparativo ao Projeto Político Pedagógico que servem de guia para organizar a proposta legal das escolas, mostrando que nele encontramos resquícios ou semelhanças propostas ao que determinava o Ratio Studiorum. Destacando e contextualizando os fatos históricos a influenciarem na sua construção, bem como sua influência para o sistema da educação no Brasil. Dados que evidenciam o percurso traçado até a publicação final, e que reflete até os dias atuais seu ensino tradicional.

Palavras-chave: Pedagogia Jesuítica. Ratio Studiorum. Educação Brasileira.

\section{A Study on Jesuit Pedagogy: the Ratio Studiorum and a Brief Comparative on the Political Pedagogical Project}

\begin{abstract}
This article aims to reflect on a historical approach to the Ratio Atque Institutio Studiorum Societatis Iesu dating from 1599, valid for all the schools of the Society of Jesus. The Ratio Studiorum meant "Study Rule"; "Order of Studies"; "Study Plan of the Society of Jesus," a comparison to the Political Pedagogical Project that serve as a guide to organize the legal proposal of schools, showing that there are traces or similarities proposed to what determined the Ratio Studiorum. Highlighting and contextualizing the historical facts to influence its construction, as well as its influence for the education system in Brazil. Data that show the path traced until the final publication, and that reflects until the present day its traditional teaching.
\end{abstract}

Keywords: Jesuit pedagogy. Ratio Studiorum. Brazilian Education.

\footnotetext{
${ }^{1}$ Graduado em Ciências Sociais pela Universidade Regional do Cariri, Especialista em Políticas Públicas, Gestão e Serviços Sociais pela Universidade Cândido Mendes. Aluno do Programa de Mestrado Profissional em Educação - MPEDU da URCA. Leilson - leilson_barros@hotmail.com;

${ }^{2}$ Graduado em Geografia pela Universidade Regional do Cariri, Especialista em Ensino de Geografia pela Faculdade de Juazeiro do Norte, Especialista em Ecologia pela Universidade Regional do Cariri e Especialista em Docência do Ensino Superior e Gestão Escolar com ênfase em Gestão Educacional. Pela Faculdade Evangélica do Piauí. Aluno do Programa de Mestrado Profissional em Educação - MPEDU da URCA. Osvaldo - educar.geoecologia@ hotmail.com;

${ }^{3}$ Graduada em Ciências Biológicas pela Universidade Regional do Cariri. Aluna do Programa de Mestrado Profissional em Educação - MPEDU da URCA. Micaela - micaela_lemos@hotmail.com
} 


\title{
Introdução
}

A Companhia de Jesus foi fundada por Santo Inácio de Loyola, em 1552, o objetivo da criação da Companhia de Jesus era desenvolver regras disciplinares para a vida religiosa e, sobretudo, para missões de evangelização. Com a fase de prosperidade da missão Jesuítica no Brasil, a Companhia de Jesus deu início à elaboração de um plano geral de estudos a ser implantado em todos os colégios da Ordem em todo o mundo, conhecido como Ratio Studiorum (SAVIANI, 2013).

\begin{abstract}
O processo de elaboração, entretanto, foi bem anterior a essa data. Desde a fundação do primeiro colégio destinado a não internos em Goa, no ano de 1543 por Francisco Xavier, surgiu uma necessidade de regulamentação de tais estudos, tendo em vista que para os noviços, já existiam as Constituições... e os Exercícios Espirituais para regular a vida em comum e comportamentos dos membros da Ordem e aspirantes (TOLEDO, 2000, p. 182).
\end{abstract}

Antes do Ratio Studiorum, existiam o modus italicus e o modus parisiensis. (SAVIANI, 2013). Mas apresentava uma estrutura que dimensionava toda uma organização destinada a um domínio e monopólio de um território que a Igreja comandava. Apresentava-se:

O Modus Italicus teve origem na Região Italiana e prevaleceu ao longo da Idade Média até o final do século XV, não seguia um programa estruturado, ou seja, podiam passar de disciplina para disciplina sem pré-requisito, tinham, também, um preceptor e um conjunto de discípulos, todos reunidos sem separação de formação ou idade. A partir do século XVI, o modus italicus foi sendo substituído pelo modus parisiensis (OLIVEIRA; COSTA, 2015; SAVIANI, 2013).

O Modus Parisiensis teve origem com o Padre Nadal e outros padres que deram início ao primeiro colégio dos Jesuítas em Messina. Nadal havia estudado na Universidade de Paris, por isso o método do modus parisiensis. Permaneceram por um bom tempo, pela sua eficiência em matéria de repetição, disputas, composição, interpretações e declamações para o aprendizado da gramática latina.

O ensinar comportava como aspectos básicos, a distribuição dos alunos em classes, realização, pelos alunos de exercícios escolares e mecanismos de incentivo ao trabalho escolar. A organização das classes dava-se pela reunião de alunos aproximadamente da mesma idade e com mesmo nível de instrução; tinham um programa previamente fixado composto por um 
conjunto de conhecimentos proporcionais ao nível dos alunos, sendo cada classe regida por um professor (OLIVEIRA; COSTA, 2015).

O modus parisiensis tinham como pilares: a lectio (leitura); a disputatio (exames das questões suscitadas na lectio); repetitiones (pequenos grupos de alunos, repetiam as lições explanadas pelo professor diante dele ou de um aluno mais adiantado). Os mecanismos de incentivo ao estudo implicavam castigos corporais, prêmios, louvores e condecorações, além da prática da denúncia ou delação. O modus parisiensis contém o germe da organização do ensino que veio constituir a escola moderna, edifícios específicos, classes homogêneas, progressão dos níveis de escolarização, series, programas sequenciais ordenando conhecimento ministrado por determinado professor (SAVIANI, 2013).

O Ratio Studiorum possui 467 regras. Passou por várias versões até ser editada e promulgada em 1599. Era de caráter universalista e elitista. Universalista por ter sido um plano adotado indistintamente por todos os jesuítas, qualquer que fosse o lugar onde estivesse e elitista, pois era dedicada somente a educação dos filhos dos colonos (SAVIANI, 2013). Uma educação que era ofertada a quem pudesse pagar ficando clara a educação excludente que já se apresentava nesse período, a educação não era pra todos.

O Plano começava com o curso de humanidades, "estudos inferiores" atual nível médio. Seu currículo abrangia cinco classes ou disciplinas: retorica; humanidades; gramática superior; gramática média e gramática inferior. Filosofia e teologia, "estudos superiores". No $1^{\circ}$ ano estudava-se logica e introdução as ciências; $2^{\circ}$ ano: cosmologia, psicologia, física e matemática; $3^{\circ}$ ano: psicologia, metafisica e filosofia moral. O currículo teológico tinha duração de quatro anos: teologia escolástica por 4 anos; teologia moral 2 anos; sagrada escritura 2 anos, leitura hebraica por 1 ano (SAVIANI, 2013).

No Brasil, apresentava a seguinte oferta e organização: os cursos de filosofia e teologia eram, na prática, limitados à formação dos padres catequistas. No período colonial se organizou o curso de humanidades (estudos inferiores) por 6 a 7 anos; gramática 4 a 5 séries gramática inferior, média e superior - assegurar expressão clara e precisa.

A dialética chamada no Ratio de humanidades, assegurar a expressão rica e elegante. A retórica - garantir a expressão poderosa e convincente. Latim e grego - disciplinas dominantes. O padre Leonel Franca, 1952, o Ratio Studiorum, desempenhou um papel de grande importância no desenvolvimento da educação moderna. passando a ser conhecido na modernidade, como pedagogia tradicional (SAVIANI, 2013). Com esse método expansionista 
de educação, os jesuítas utilizavam como método que representou uma rígida padronização dos trabalhos pedagógicos de forma sistêmica e estruturada.

\section{As Influências no Surgimento do Ratio Studiorum}

A Ratio atque Institutio Studiorum Societatis Iesu configura-se em um Plano e Organização de Estudos da Companhia de Jesus, normalmente abreviada como Ratio Studiorum. Seu surgimento é influenciado por mudanças significativas ao longo processo histórico educacional nos colégios europeus, gerando consequentemente, mudanças na forma de ensinar e criando programas de estudos que são fatores importantes na institucionalização de uma pedagogia jesuítica.

Podemos observar que um dos primeiros fatos históricos a influenciarem na construção do Ratio Studiorum ocorreu em 1509 com a substituição dos métodos de ensino, pois antes tinha como parâmetro o modus italicus que passa a ser substituído gradativamente pelo modus parisiensis. Com o fim da Idade Média, surge com ele a necessidade de transformação.

O modus italicus foi referência como forma de ensino no decorrer de toda Idade Média até o final do século XV. Esse método foi desenvolvido na Itália e tinha como característica não seguir um programa que trouxesse uma estrutura pronta, para que também pudesse dar possibilidade de uma maior liberdade ao preceptor responsável pela instrução, com isso não buscava vincular o discípulo as disciplinas, ou seja, não havia uma exigência para passar a outra disciplina, também não era uma separação feita em classes, o que não excluía a possibilidade de se ter discípulos de idades diferentes acompanhados pelo mesmo preceptor.

A partir do início século XVI, o modus italicus foi sendo progressivamente suplantado pelo modus parisiensis, que tem esse nome porque se refere ao método adotado na capital da França, tendo se tornado a marca distintiva da Universidade de Paris (SAVIANI, 2008).

As transformações começam a acontecer pela forte influência da Universidade de Paris, pois os Jesuítas que iniciam a institucionalização de uma pedagogia própria estudaram em Paris e adotaram o modus parisiense como forma de orientar a estrutura dos seus colégios.

O modus parisiense trazia alguns aspectos básicos. Um desses aspectos e que se distancia completamente do modus italicus é a separação em classes. Essas classes eram regidas 
por um professor e tinham alunos de mesma idade e com mesmo nível de instrução. A escolástica é uma forte influência nesse método, pois ele adota os exercícios escolares como forma de preleção dos assuntos a ser estudados, como também a utilização de exames avaliativos e exercícios de repetição. Como forma de disciplina, eram aplicados mecanismos de incentivo que podiam ser castigos corporais ou premiações.

A vivência por parte dos jesuítas com esse método adotado pela Universidade de Paris, fez com que se tornasse um instrumento norteador para a construção de um programa que viesse contemplar a forma de educação almejada nos colégios jesuíticos.

Os pioneiros na organização dos planos de estudos foram os Colégios de Messina e mais tarde Palermo (1548-1549). A vivência em Messina serviu como protótipo para a pedagogia jesuítica, pois a partir dela é elaborado o primeiro plano de estudos por P. Nadal em 1551. Em virtude dessas novas influências S. Inácio funda o Colégio Romano que é responsável pela formação de professores, se tornando depois a Pontifícia Universidade Gregoriana - PUG.

O principal objetivo a ser alcançado nesse primeiro momento de institucionalização é a uniformização dos colégios em toda Europa, sendo buscado por P. Nadal promulgar as Constituições das Companhias. Com isso se tem uma rápida expansão e esses colégios começam a ganhar importância. Antes de sua morte $\mathrm{S}$. Inácio deixa 33 colégios constituídos e 6 aprovados, incluindo o de São Paulo (fundado pelo Padre Emanuel da Nóbrega, em 1554). A amplitude do projeto também traz novas problemáticas quanto à organização e relação governamental.

\section{A Elaboração do Ratio Studiorum}

A adequação do Plano de Estudo de Messina foi realizada em virtude das diversidades de costumes, alterando a sua forma original para responder as necessidades dos Jesuítas. Como forma de manutenção na uniformidade da estrutura e a eficiência pedagógica, foram criadas comissões que pudessem acompanhar e inspecionar o andamento da institucionalização do método.

Entre 1564 e 1684 tivemos as mudanças nas organizações e adequação governamental. O Plano de Redízima em que a Coroa Portuguesa instituiu que $10 \%$ dos impostos arrecadados 
passassem a ser destinada a manutenção dos colégios Jesuíticos. O dinheiro foi muito favorável na medida em que também contribuiu na alimentação; vestuário e calçado; remédios e assistência hospitalar; viagens por terra; viagens por mar; colégios e casas da Companhia de Jesus.

As Congregações Gerais dos Jesuítas buscam codificar todo material pedagógico existente. P. Everardo Mercuriano esboça uma legislação geral e uniforme para toda a companhia em 1577, para que se possa ter organização na construção d documento final.

Em 1584 é nomeada uma comissão para elaborar um plano de estudo com base em estatutos, regulamentos dos colégios, ordenações, usos e costumes locais, acumulados em 40 anos de trabalho educativo, um dos fatores de fortalecimento do Plano, pois buscavam adaptarse à realidade em que estavam inseridos.

A primeira apreciação em relação ao plano de estudos pela Companhia foi realizada em 1586, e foi colocado como caráter provisório, sem força de lei. Essa versão serviu como forma de discussão para que fosse construído um plano baseado em relatórios, que por sua vez, continham relatos longos que orientaram a elaboração do documento final.

Enviou-se, em 1591, nova redação refeita com muitas observações. Chama-se Ratio atque Institutio Studiorum Societatis Iesu . É um plano de estudos, um texto normativo usado como experiência por três anos. P. Claudio Acquaviva promulga o texto definitivo do Ratio, após 15 anos de elaboração, com ampla participação da Companhia, decorridos 50 anos da fundação do $1^{\circ}$ colégio jesuíta. Nessa ocasião havia 245 colégios jesuítas. Esse código de leis vigorou quase 200 anos até a supressão da Ordem, em 1773. Quando foi supressa, a Companhia tinha 865 estabelecimentos de ensino.

\section{Organização e Plano de Estudos da Companhia de Jesus}

Como foi relatado anteriormente o Ratio Studiorum possui 467 regras, divididas em: 25 Regras do Provincial, 24 Regras do Reitor, 30 Regras do Prefeito de Estudos, 20 Regras Comuns a Todos os Professores das Faculdades Superiores, 20 Regras do Professor de Sagrada Escritura, 5 Regras do Professor de Língua Hebraica, 14 Regras do Professor de Teologia, 10 Regras do Professor de Casos de Consciência (Teologia Moral), 20 Regras do Professor de 
Filosofia, 4 Regras do Professor de Filosofia Moral, 3 Regras do Professor de Matemática, 50 Regras do Prefeito de Estudos Inferiores, 11 Normas da Prova Escrita, 13 Normas para a Distribuição de Prêmios, 50 Regras Comuns aos Professores das Classes Inferiores, 20 Regras do Professor de Retórica, 10 Regras do Professor de Humanidades, 10 Regras do Professor da Classe Superior de Gramática, 10 Regras do Professor da Classe Média de Gramática, 9 Regras do Professor da Classe Inferior de Gramática, 11 Regras dos Escolásticos da Nossa Companhia, 14 Diretrizes para os que repetem privadamente a teologia em dois anos, 7 Regras do Ajudante do Professor, 15 Regras dos alunos externos da Companhia, 12 Regras da Academia, 5 Regras do Prefeito da Academia, 11 Regras da Academia dos Teólogos e Filósofos, 4 Regras do Prefeito da Academia dos Teólogos e Filósofos, 7 Regras da Academia dos Retóricos Humanistas e 8 Regras da Academia dos Gramáticos (FRANCA, 1952).

As estruturas do Ratio Studiorum atendem a um princípio de autoridade hierarquizada. Até mesmo a disposição das regras se encontra dessa maneira. O primeiro conjunto de regras é dirigido ao Provincial, em seguida são expostas as regras do Reitor, do Prefeito de Estudos, e logo depois aponta as regras comuns aos professores de classes superiores. Só depois de tratar das particularidades dos professores de cada área dos cursos superiores é que se destina aos professores de classes inferiores (LIMA, 2008).

De acordo com Leonel Franca o "Ratio Studiorum" não se constitui num tratado de pedagogia, pois não discute princípios educacionais nem expõe sistemas; sendo um Programa de Estudos formado por uma coleção de regras positivas e uma série de prescrições práticas e minuciosas. Mesmo não enunciando princípios pedagógicos podemos lê-los nas entrelinhas de sua organização

\section{Um Comparativo aos Instrumentos Norteadores Contemporâneos}

O Ratio Studiorum foi um instrumento norteador para a consolidação da Educação Jesuítica. Como sabemos da influência direta na construção de uma Educação Brasileira, não é surpresa encontrarmos elementos desse plano nos instrumentos atuais. Sabemos dos inúmeros documentos norteadores, por isso será feito um comparativo do Plano Institucional dos Jesuítas 
que serviram de parâmetros para os colégios da época, com um instrumento que hoje serve para suprir essas mesmas necessidades, o Projeto Político Pedagógico - PPP.

De início é importante destacar o funcionamento das instituições a partir desse instrumento, para que possamos trazer elementos que ainda se fazem presentes nos instrumentos de hoje.

A escola passou a se responsabilizar pelo conhecimento formal, ou seja, é através da formalização da Educação que essa instituição visa formar o ser humano nas dimensões cognitiva, afetiva, social, psicológica, ética, estética entre outras. Nesse processo formativo envolver todos os segmentos que compõe essa construção, faz com que o "fazer educativo" possa ser planejado, executado, acompanhado e avaliado durante toda a caminhada.

Isso não se distancia do que foi realizado através da adequação do Plano de Messina por parte da Companhia de Jesus, pois considerar a diversidade de costumes na época favoreceu para o levantamento das formas de ensinos que eram desenvolvidos nos colégios europeus. Por isso, na construção de um PPP não se deve concentrar essa responsabilidade apenas para a gestão, mas trazer toda a comunidade escolar para conversar e construir juntos. É importante destacar que “[...] a participação só tem sentido quando existe por detrás uma ética, uma disposição em mudar realmente o que for necessário e não apenas as aparências" (VASCONCELLOS, 2009).

A participação no processo de construção desse documento é importante, pois só assim serão percebidas as necessidades reais que influenciarão diretamente na construção do PPP, visto que reafirma os objetivos da escola e as ações que serão desenvolvidas para alcançar esses objetivos, considerando que: o projeto não se concretiza "na simples produção de um documento, mas na consolidação de um processo de ação-reflexão-ação, que exige o esforço conjunto e a vontade política do coletivo escolar" (VEIGA, 2003).

No processo de construção do Ratio Studiorum, antes dele tomar caráter de lei, passou por apreciação e após ser institucionalizado serviu como experiência por três anos para ser reavaliado novamente. Por isso, essa estrutura permaneceu por 200 anos, não somente por imposição, mas por ter sido planejado e bem elaborado a luz das necessidades percebidas pelos Jesuítas em sua época.

Vale salientar que para um PPP refletir de fato a realidade institucional, deve ser construído baseado no contexto real em que a escola está inserida. Percebemos que esses 
instrumentos não servem ao que se propõe, pois são tratados apenas como documentos burocráticos que não orientam de fato o trabalho realizado dentro da instituição.

O PPP é um conjunto de concepções adotadas pela escola que explicita sua função social e que orienta as práticas pedagógicas, didáticas e metodológicas, que serão desenvolvidos no que se refere ao processo educativo tendo como principal foco o processo de ensino e aprendizagem.

O que se pretende é evidenciar que toda a estrutura apresentada pela Pedagogia Jesuítica transformou a forma de se enxergar os métodos pedagógicos para alcançar a efetiva aprendizagem do aluno. Não estamos aqui detalhando os desafios de incluir os grupos que não participaram ao longo da história dessa formação, pois sabemos que caberiam inúmeras páginas para relatar a elitização da educação, porém queremos destacar que toda essa estrutura apresentada há mais de 500 anos, ainda está presente na construção de uma educação que cumpra com sua função social nos dias de hoje.

Nessa perspectiva, Gadotti afirma: "elaborar o PPP da escola é pensar um futuro diferente do presente, é projetar-se em busca de uma nova realidade, em função da promessa de que cada projeto contém um futuro melhor do que o presente" (GADOTTI, 1997).

\section{Considerações Finais}

O Ratio Studiorum teve como destaque em sua proposta educacional o longo período de tempo que ficou em vigor, como também uniformidade e eficiência alcançada nos muitos colégios jesuítas. Com isso, não foi apenas uma Plano que visava limitar sua forma de ensino como era desenvolvida na escolástica, mas sim atingir a um número de instituições significativas e construir uma Pedagogia consolidada e institucionalizada.

Ao mesmo tem que essa Ordem de Estudos obedecia ao método dos padres, conseguiam atingir a estrutura vigente e modificá-la no que tange aos campos social, econômico e cultural. Por isso, os dados apresentados evidenciam todo o percurso que foi traçado até a publicação final de um documento que reflete até os dias atuais no ensino tradicional.

Avaliar os instrumentos norteadores da educação já é um desafio com todas as informações que temos hoje. Tratar sobre a Educação Jesuítica requer um estudo muito mais aprofundado, porém acreditamos que esse material traz informações importantes para 
entendermos como ao longo da história tivemos influências que causaram toda a revolução na educação formal. Por isso, os instrumentos norteadores para uma educação libertadora devem ser tratados, principalmente buscando mudar a realidade a qual está inserida.

\section{Referências}

FRANCA, L. S. J. O Método Pedagógico dos Jesuítas - $O$ "Ratio Studiorum”. Introdução e Tradução. Rio de Janeiro: Livraria AGIR Editora, 1952.

GADOTTI, Moacir. Pressupostos do projeto pedagógico. In: MEC, Anais da Conferência Nacional de Educação para Todos. Brasília, 1994.

LIMA, D. F. C. F. O homem segundo o Ratio Studiorum. Dissertação de mestrado, UNIMEP, 2008.

OLIVEIRA, N. C. O. COSTA, C. J. Sistema de ensino inaciano e o Ratio Studiorum. Seminário de Pesquisa do PPE. Universidade Estadual de Maringá. 2015.

SAVIANI, D. História das Ideias Pedagógicas no Brasil. 4 ed. Campinas, SP: Autores Associados, 2013.

TOLEDO, C. A. A. Razão de estudos e razão política: um estudo sobre a Ratio Studiorum Acta Scientiarum. 22(1):181-187, 2000.

VASCONCELLOS, C. S. Coordenação do Trabalho Pedagógico: do projeto políticopedagógico ao cotidiano da sala de aula. $11^{\text {a }}$ ed. São Paulo: Libertad Editora, 2009.

VEIGA, Ilma P. A. Inovações e Projeto Político Pedagógico: uma relação regulatória ou emancipatória? Caderno Cede, Campinas, v. 23, n. 61, p. 267 - 281, dezembro 2003.

\section{Como citar este artigo (Formato ABNT):}

OLIVEIRA, Leilson Barros; LIMA NETO, Osvaldo Bezerra; LEMOS, Sebastiana Micaela Amorim. Um Estudo sobre a Pedagogia Jesuítica: o Ratio Studiorum e um breve Comparativo ao Projeto Político Pedagógico.. Id on Line Rev.Mult. Psic., 2018, vol.12, n.41, p.627-636. ISSN: 1981-1179.

Recebido: 10/07/2018

Aceito 11/07/2018 